\title{
A market-led approach to female student recruitment onto computing-related courses
}

\author{
S. Stocking, N. Stanton \& L. Seldon \\ School of Computing, University of Glamorgan, Wales
}

\begin{abstract}
In recent years, numbers of students applying for undergraduate courses in computing have continued to fall. Research shows that this is particularly true for female students. This is a national trend and must be a matter of concern for Higher Education Institutions. It can been seen that the number of girls selecting computing-related courses at GCSE and A level is less than that of boys, and this difference gets greater at HND and degree level. We believe that there are a number of issues that are contributing to this decline. For example, computing suffers from an increasingly-poor public image and this has adversely affected pupils' perception of the computing industry. We also believe that pupils are often misinformed about the syllabi of computing courses and about the benefits of taking them in Higher Education (HE). The purpose of this research is to investigate the attitude of female pupils towards computing so that an action plan can be produced for the School of Computing to encourage more females onto their courses.

Keywords: computing, recruitment, female, gender, perceptions, attitudes, higher education, GCSE, A level, ICT.
\end{abstract}

\section{Introduction}

Statistics at the moment show that only $40 \%$ of GCSE ICT and Computing entrants are girls. The situation becomes worse at college, where, for example, only $22 \%$ of A-level candidates are female [4].

Social and cultural research has shown that although the numbers graduating with degrees in computer science is dropping for both sexes, the number of degrees awarded to women is dropping faster. This research has also shown that 
only 1 in 20 computing professors, 1 in 8 computing researchers and 1 in $4 \mathrm{PhD}$ students are female [5], even though, in computing, 33\% of women aspire to leadership positions and only $22 \%$ of men do.

Higher Education Institutions are also concerned about the retention rate of first-year computing students [6]. There have been a number of surveys carried out into reasons for dropping-out of HE courses and this research has shown that wrong choice of course is the reason why a significant number of students drop out in the first year. Davies and Elias [7] state that $24 \%$ of students drop-out for this reason; Yorke [8] gives a figure of $39 \%$. There can be a number of contributing factors, but one of them is misinformed preconceptions about what computing courses entail [9]. In order to attract female students onto its courses, it is important, therefore, that the School of Computing provides good information to prospective students so that they can make informed choices about courses. This requires the School to know what their potential students think and know about computing and computing courses.

The aim of our research is to investigate the perceptions held about computing by female pupils in years 11,12 and 13 .

\section{Methodology}

The research was carried out by running focus groups and conducting a survey. Two hundred and fifty pupils from eight secondary schools took part in the initial research (focus groups). The schools were located throughout South East Wales, and the pupils themselves came from a variety of backgrounds. The information gained from these focus groups was used to inform the development of a questionnaire that was distributed to many more schools in the area. The results of the questionnaires were analysed and used to develop an action plan.

Students were allocated to one of four, mixed-sex groups:

- year 11 students taking ICT or Computing at GSCE;

- year 11 students not taking either ICT or Computing at GSCE;

- year 12 and 13 students taking either ICT or Computing at A level;

- year 12 and 13 students not taking either ICT or Computing at A level.

The number of focus groups held in each school varied depending on the number of students available to participate in the groups and what subjects were offered by the school (not all schools teach ICT and Computing).

The purpose of the focus groups was to identify the reasons why or why not female pupils choose to take ICT or Computing. The results were then used to develop the questionnaire.

The questionnaires were distributed to schools throughout the area. Fortytwo sets of questionnaires were sent out and 23 were returned (57\% return) from both male and female pupils. The results from the questionnaires received from the pupils were then transcribed into a spreadsheet and analysed. 


\section{Findings}

\subsection{Findings from the survey}

\subsubsection{Year 11 Pupils}

The questionnaires were completed by 417 students. Of these, 184 (44\%) were female and $233(56 \%)$ were male. The number of students studying GCSE ICT or Computing was 340, and, of these, 140 (41\%) were female and $200(59 \%)$ were male.

In order of popularity, the top five reasons given by female pupils for taking GCSE ICT or Computing are given below. Where the reasons given by males differ from those given by females, they are indicated in brackets.

1. Offers good job prospects

2. Liked the subject (Liked the subject)

3. Enjoyed previous computing classes

4. Want to study at a higher level

5. Recommended by family (Offers good job prospects)

In order of popularity, the top five reasons given by female pupils for not taking GCSE ICT or Computing are given below. Where the reasons given by males differ from those given by females, they are indicated in brackets.

1. Clashed with other options

2. Did not enjoy previous computer classes

3. Do not want to study it at a higher level

4. Too much work involved

(Other)

5. Poor image - geeky and/or boring

\subsubsection{Year 12 and 13 pupils}

The questionnaires were completed by 588 students. Of these, 225 (38\%) were female and $363(62 \%)$ were male. The number of students studying A level ICT or Computing was 373, and, of these, $110(29 \%)$ were female and $263(71 \%)$ were male.

In order of popularity, the top five reasons given by female students for taking A level ICT or Computing are given below. Where the reasons given by males differ from those given by females, they are indicated in brackets.

1. Thought it would be useful

2. Offers good job prospects

3. Liked the subject

(Liked the subject)

4. Enjoyed it at GCSE level

5. Did well at it at GCSE level

(Offers good job prospects)

(Want to study it at a higher level) 
In order of popularity, the top five reasons given by female students for not taking A level ICT or Computing are given below. Where the reasons given by males differ from those given by females, they are indicated in brackets.

1. Do not want to study it at university

2. Did not enjoy studying it previously

3. Subject didn't live up to expectations

4. Did not take it at AS level

(Too much work involved)

5. Too much work involved

(Clashed with other options)

(Did not do well at it

previously)

\subsection{Discussions with pupils and teachers}

From the research already conducted, it is clear that there are a number of misunderstandings about the content of GCSE, A level and HE computing courses. The researchers believe that this is having a detrimental effect on students' career choices and the quality of cohorts recruited onto computing courses at the University of Glamorgan. A need to recruit the right students is also evidenced by the work of Anna Round [10].

The principal confusion in schools is between ICT and Computing. It is felt that teachers often do not understand the difference and this results in pupils making inappropriate subject choices. Computing includes programming, which can be a stumbling block for many who wish to take a computing course (ICT does not). Many students in Higher Education are happy to take businessfocussed computing courses rather than technically-focussed courses such as network management and programming. However, if pupils do not understand the basic choice between ICT and Computing at school, mistakes will be made and pupils will discount the idea of taking computing courses later on.

The issue of course titles is also a challenge to students entering Higher Education. The School of Computing offered 15 awards in its BSc (Hons) Scheme in $2005 / 6$. This number is due to increase to 21 with the introduction of a new scheme in September 2006. The increase in the number of awards is market-led in the sense that it allows more choice, but this degree of choice can be confusing for students who are seeking to understand the differences between courses in order to find out which course is the most appropriate for them.

\section{Conclusions}

\subsection{Year 11 pupils}

Considering first the top-five reasons why year 11 pupils choose ICT, the researchers believe that the School of Computing could take action to reinforce at least two of these reasons: offers good job prospects and want to study at a higher level.

The School could make a significant contribution to the first of these by ensuring that pupils are well informed about the opportunities and rewards 
offered by a career in computing. Actions to be taken could include delivering guest lectures in schools, supplying multimedia material about the IT industry to schools, developing closer relationships with schools' career advisors and offering pupils opportunities to visit our campus for taster sessions that would include an element of promotion.

The School could also do much to increases pupils' propensity to go on to Higher Education. The researchers believe that a critical success factor would be the development of good relationships with local schools and their pupils. Again, guest lecturing, relationship building with careers advisors and IT teachers, and the running of taster sessions at the University would all have a part to play in an action plan to increase the inclination of pupils to go on.

Although there is relatively little the School can do to influence the remaining three factors, the actions already described should have a positive effect. For example, running interesting and lively tasters sessions at the University may positively affect pupils' perceptions of computing and computing classes.

Turning to the reasons given for not taking computing, the most popular reason, clashes with other options, is beyond the control of the School of Computing. Timetables in schools are constrained in a number of ways, ICT and Computing are not core curriculum subjects and the School of Computing has little opportunity to influence school timetables.

The next two reasons - enjoyment and studying at a higher level - mirror two of the most popular reasons given for taking ICT or Computing. Actions to deal with the negative perceptions would be the same as those previously described to make the most of their positive counterparts.

The fourth issue, too much work involved, is beyond the direct control of the School. However, research ongoing elsewhere in the School, on behalf of the Welsh Joint Education Committee (WJEC), is looking at the workload involved in studying ICT and Computing at GCSE and A level. Initial indications from this research are that the workload in each school varies beyond acceptable limits [11].

The last reason, poor image, is an issue that can be addressed. The stereotypical image of an anti-social individual who spends hours in front of a computer screen is often unattractive to pupils, but the reality of professional life in the IT industry may be quite different, and the School of Computing can do much to open pupils' minds to the range of roles available, from technical specialists to client-facing roles. A perception that computing is all about highlytechnical specialisms is one that needs to be dispelled.

\subsection{Year 12 and 13 pupils}

A number of interesting themes emerge from the analysis of results for students taking A level ICT or Computing. First, the top four results evidence a duality of liking the subject and believing it to be a useful choice. These are things can be reinforced by the School through engaging pupils as described previously.

The fifth most-popular reason evidences a need for pupils to be encouraged to believe that they can succeed in their chosen subject. From the School's viewpoint, it is important to note that the taster sessions should be designed to 
leave the students with a sense of achievement and a hope that they could succeed if they were to gain entry onto a course in the School.

Turning to the reasons given for not taking computing, the top reason displays a natural focus on careers that one would expect from a group of A level students. The three reasons that follow can be summarised as not enjoying the subject for one reason or another.

The opportunity for the School to influence this group has now passed; however, it does evidence a need to excite and enthuse pupils about computing before they get to this point.

\subsection{Action plan}

The plan of action proposed for the School of Computing is as follows.

1. Appointment of a schools liaison officer who is responsible for ensuring that relationships are built and maintained with selected local schools. The principal relationships would be with deputy heads, heads of year 9 , IT teachers and careers advisors.

2. Selection of and distribution of promotional material on the IT industry to IT teachers and careers advisors.

3. Running of taster sessions during the summer for pupils who have just entered year 12. (After this programme has been piloted this would be extended to include year 11 pupils.)

4. Running of topical short courses for ICT and computing teachers.

\subsection{Further research}

Three complementary studies have been carried out in this area by Round [12], Mitchell [13], and Lovegrove and Round [14].

The first investigated pupils' attitudes to computing and gave some useful insights into why pupils choose (or not) to take GCSE ICT or Computing. The sample was drawn from a number of schools in North-East England, South-East England and Wales.

The second investigated the perceptions of computer science pupils in secondary schools in Scotland. There is an encouraging degree of similarity between the findings of this study and the ones presented here. For example, Alison Mitchell identifies the reasons for a decline in recruitment onto HE computing courses as including being boring, not knowing what it involves and being too difficult.

The third study, which builds on the work of Alison Mitchell, focuses on gender inclusion, cultural inclusion and employment opportunities.

Clearly there is a developing interest in this area and therefore there is an opportunity for collaboration throughout the UK. 


\section{References}

[1] UCAS, 2005. Applications and acceptances by subject [online]. Cheltenham. Available from: http://www.ucas.ac.uk/figures/reports/ applications.html [Accessed 7 December 2005]

[2] Clark, L., 2004. Doctors chief warns of potential NHS IT plan failure [online]. Sutton, Computer Weekly. Available from: http://www.computerweekly.com/articles/article.asp?liArticleID=134742 \&liArticleTypeID=1\&liCategoryID=2\&liChannelID=28\&liFlavourID $=1$ $\&$ sSearch $=\&$ nPage $=1$ [Accessed 7 December 2005]

[3] Riley, J., 2005. Aspiring to a culture of professionalism [online]. Sutton, Computer Weekly. Available from: http://www.computerweekly.com/ Articles/2005/10/11/212233/Aspiringtoacultureofprofessionalism.htm [Accessed 7 December 2005]

[4] Bolton University, 2005. Babes in IT [online]. Available from: http://www.bolton.ac.uk/wict/babes/html/home.htm [Accessed 20 March 2006]

[5] British Computer Society (BCS), 2005. Computer Scientist and a Woman? [online]. Swindon. Available from: http://www.bcs.org/ server.php?show=ConWebDoc.2977 [Accessed 12 April 2006]

[6] Department for Education and Skills, 2003. The Future of Higher Education: Response To The Report From The Education And Skills Committee, Fifth Report Of Session 2002-03 [online]. London. Available from: http://www.dfes.gov.uk/hegateway/searchresults.cfm?qt=student + retention $\& x=15 \& y=12$ [Accessed 11 April 2006]

[7] Davies, R. and Elias, P., 2003. Dropping Out: A study of early leavers from Higher Education [online]. London, Department for Education and Skills. Available from: http://www.dfes.gov.uk/research/programme ofresearch/projectinformation.cfm?projectid $=13604 \&$ resultspage $=1$ [Accessed 12 April 2006].

[8] Yorke, M., 2006. Increasing the chances of student success in the first year of full-time study [online]. Leeds University. Available from: www.leeds.ac.uk/sddu/teachtalk/MYorke-Handout.ppt [Accessed 11 April 2006]

[9] Higher Education Academy (HEA), 2004. Student Retention [online]. York. Available from: http://www.ics.heacademy.ac.uk/student_retention/ home/index.htm [Accessed 15 December 2005]

[10] Round, A., 2004. Student Recruitment for Student Retention [online]. York, Higher Education Academy. Available from: www.ics.heacademy.ac.uk/student_retention/workshops/pres/Anna\%20Ro und.ppt [Accessed 12 April 2006]

[11] Welsh Joint Education Committee (WJEC), 2006. Credit and Qualification for Wales: Credit in General Qualifications. Cardiff, unpublished. 
262 Data Mining VIII: Data, Text and Web Mining and their Business Applications

[12] Round, A., 2005. Attitudes to Computing Courses and Careers Among Secondary School Pupils [online]. Swindon, BCS. Available from: www.bcs.org/upload/ppt/schoolssurvey.ppt [Accessed 12 April 2006]

[13] Mitchell, A., 2004. Computer Science: What do pupils think? [online]. Leeds University. Available from: www.comp.leeds.ac.uk/roger/Files/ AlisonMitchell.ppt [Accessed 12 April 2006]

[14] Lovegrove, G. and Round, A., 2005. Increasing the supply of undergraduates [online]. Swindon, BCS. Available from: http://www.bcs.org/upload/pdf/itprofnewcastle.pdf [Accessed 12 April 2006] 